\title{
Brand Competition in CPG Industries: Sustaining Large Local Advantages with Little Product Differentiation
}

\author{
Bart J. Bronnenberg* \\ UCLA Anderson Graduate School of Management \\ bart.bronnenberg@anderson.ucla.edu.
}

7 June 2006

\begin{abstract}
In direct competition between national brands of consumer packaged goods (CPG), one brand often has a large local share advantage over the other despite that the products are similar. I present an explanation for these large and persistent advantages in the context of local competition on perceived quality or brand image. The main result of the analysis is a relation between varying degrees of horizontal product differentiation and local share advantages. Namely, I find that local share advantages can be sustained especially if competing brands are objectively similar. Conversely, local share advantages can not be sustained if brands are dissimilar. This paper provides two independent intuitions for this result. First, if brands are objectively similar, different levels of investments in local quality perceptions can co-exist in the same market. Specifically, if it pays to do so, early movers will invest in high perceived quality. Late movers have reduced incentives to invest because of subsequent demand sharing and price competition. Second, if the perceived quality advantages are geographically distributed across competitors, the above argument is reinforced by multimarket contact. Even if local "brand building" is free, firms have an incentive to sustain asymmetric market shares because, holding total demand constant, multimarket profits are increasing in share variation, i.e., monopoly power, across regions. This increase is steeper when the products are similar, because price competition looms large.
\end{abstract}

JEL Classification: L11, L15, L22, L66, M30, R12

\section{Introduction}

Brands of consumer package goods (CPG) in the United States often lack meaningful product differentiation on attributes other than brand labels and would be difficult to recognize based on taste

${ }^{*}$ I would like to thank Ronald Cotterill from the Food Marketing Policy Center for the use of his data. Discussions with and comments from Pradeep Bhardwaj, Pradeep Chintagunta, Jean-Pierre Dubé, Vrinda Kadiyali, and Adam Rennhoff are gratefully acknowledged. The paper benefited from comments made by seminars participants at CarnegieMellon University, Duke University, Emory University, Erasmus University Rotterdam, Northwestern University, the Wharton School, the University of California at Berkeley, the University of Michigan, and the University of Toronto. Errors are mine. A practitioner note on this paper, based on an early version of it, was written by Booz $\mid$ Allen|Hamilton and is available from www.strategy-business.com/media/file/sb34_041-research_notes.pdf 
tests alone (Carpenter, Glazer, and Nakamoto 1994; Trout and Rivkin 2000). If two products are physically identical, except perhaps for brand labels, utility maximizing consumers should be relatively indifferent between them. All else equal, therefore, demand for such brands should be similar or at least not systematically different.

However, this simple intuition does not hold for CPG industries in two ways. First, it is not true that seemingly similar brands have the same market shares in a given market (local asymmetries). Second, the same national brand of repeat purchase goods often has very different market shares across different local markets, even after controlling for the influence of regional or local brands (spatial dispersion and spatial dependence). Consider Figure 1, which shows market shares for the two largest manufacturers of brands of Mexican salsa, Campbell and Frito-Lay, who sell the Pace and Tostitos brands, respectively. Both brands originate in Texas and offer very similar products. The figure demonstrates that the two firms have very different shares within markets. Across markets, the two firms seem to divide the domestic U.S. market in two territories, one for each brand. Tostitos dominates along the East Coast, whereas Pace leads west of the Mississippi. While local marketshares are clearly not constant across markets, they are in fact constant across time. ${ }^{1}$

Bronnenberg, Dhar and Dubé (2005) show that these patterns are commonplace in CPG industries such as coffee, mayonnaise, margarines, pickles, hotdogs, etc. Given any one market and given the similarity of most national brands in the aforementioned categories, the question addressed in this paper is: What sustains large local market advantages in the face of little product differentiation?

Traditionally, geographic concentration of sales or outputs has been linked to geographic cost differences (see e.g., Greenhut 1981). For instance, prices can be affected by the location of firms through transportation cost (Anderson and de Palma 1988; Fujita, Krugman, and Venables 1999). Thus, locating oneself closer to consumers creates a cost advantage which may impact local sales and share. In this research tradition, it is the transportation cost of firms that drives the spatial distribution of prices and outputs. However, the location of the manufacturers whose outputs are represented in Figure 1 was initially similar and therefore transportation cost of firms does not to seem to explain the observed data well.

The answers provided in this paper are twofold and focus on the interaction of product similarity (horizontal differentiation) and firms' efforts to influence perceived quality (vertical differentiation). First, the absence of horizontal product differentiation, makes the presence of vertical product dif-

\footnotetext{
${ }^{1}$ This fact is illustrated by the fact that Figure 1 represents the annual averages of market shares for 1996, suggesting that the differences in share are not simply due to temporary local marketing programs.
} 

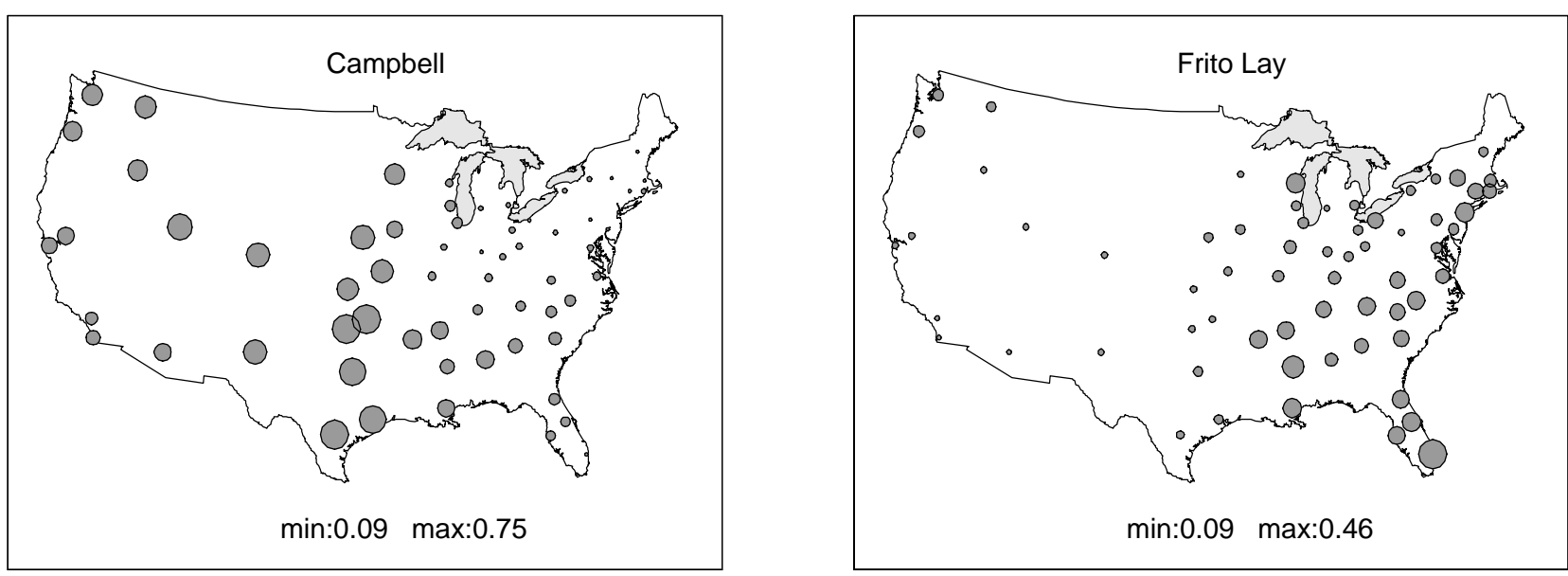

Figure 1: Market shares of two leading manufacturers of mexican salsa

ferentiation, i.e., differences in quality perceptions, effective in generating sales and profit margins. That is, I find that the lower the degree of horizontal product differentiation, the more profits increase in vertical differentiation. If quality perceptions are costly to raise, it can be shown that one firm decides to invest in high quality perceptions whereas the other chooses not to invest. This is exactly what happens in many CPG industries. In each local market, a small number of brands invests in quality perceptions through advertising and distribution whereas other products do not invest and play a fringe role (Bronnenberg, Dhar and Dubé 2005a). This creates local asymmetries where the first mover takes the high quality, high share position.

Second, I show that multimarket profits are higher when a brand's market shares have geographic variation. Thus if the national brands dominate in some markets but are dominated in others, they generally have an incentive to sustain this situation relative to having "average" share in all markets, something which requires a form of tacit collusion. It has been argued (Karnani and Wernerfelt 1985) that such multimarket coordination is at work in at least some CPG industries.

Common to these two explanations, I find that the less product differentiation, the easier asymmetric choices in perceived quality emerge and persist. In effect, by endogenizing local perceptions of product quality, the main finding of this paper is that when two products are objectively similar market shares for these products will be different. Conversely, when products are very different, market shares are similar across geography, in the sense of globally reflecting objective quality differences rather than strategically managed perceptual deviations from this objective quality.

More broadly, this paper aims to contribute to a growing literature in economics and marketing 
about the role of geography and space. For instance, the "New Economic Geography" (Fujita, Krugman and Venables, 1999) poses two fundamental questions about economic activity. These are (1) When does spatial asymmetry of economic activity emerge?, and (2) Why do spatial asymmetries in economic activity persist? In the context of the first question, I find that spatial share asymmetry emerges in the CPG industry when horizontal product differentiation is nearly absent and quality perceptions are set locally at some cost. In the context of the second question, I find that asymmetric shares for similar brands of packaged goods are stable because (i) asymmetric local investments in branding constitute an equilibrium in a single market, and in addition (ii) multimarket profits are increasing in across-market share-variability (holding demand constant).

The remainder of this paper is organized as follows. The next section reviews research advocating how consumers take non-product attributes such as advertising and distribution as perceptual cues for product quality in CPG industries. Section 3 discusses a family of demand models with local quality perceptions. Section 4 establishes the basic relation between profits, perceived quality and prices in a single market framework. Section 5 shows how asymmetric choices about local perceived quality emerge and are sustained. It also links these results to sequential entry. Section 6 shows how market share asymmetries can be sustained in a multi-market setting, even when improving quality perceptions is free. Section 7 discusses several empirical examples and interprets the main results in the context of packaged goods. Section 8 concludes.

\section{Determinants of consumer quality perceptions}

Consumers form quality perceptions from environmental cues other than the product itself. An important impetus to quality perceptions remains the physical product itself. However, the premise of this paper is that brand awareness and distribution support such as shelf-space are used by consumers as quality cues. There is ample support for advertising-driven quality inferences. For instance in marketing, Kirmani and Wright (1989) find a positive relation between advertising and expectations about product quality. Further, brand awareness is often a determinant of choice, especially for low involvement decisions (Bettman and Park 1980; Hoyer and Brown 1990; Park and Lessig 1981). In economics, an important benefit of advertising is regarded to be its capacity to increase the willingness to pay for products (for a detailed overview of this large literature see, e.g., Sutton 1991). In addition, there is a large and important literature in economics linking persuasion

advertising to product quality (Bagwell 2003; Caves and Greene 1990; Comanor and Wilson 1974). 
There are also studies linking brand distribution to perceived quality. Simonson (1993) for instance concludes that consumers construct preferences at the point of purchase. For new consumers, this means that preferences for different brands of CPG goods can be initially formed at the supermarket shelf. Shelf space allocations affect choices and perceptions of quality in such cases because consumers take large shelf space allocations of packaged goods as cues that those brands are popular in a given local market. Thus, if consumers do not acquire brand information themselves (Dickson and Sawyer 1990, Hoyer 1984), they may rely on the quality assessments of others.

In sum, while consumers from different markets may face the same physical product, perceptions about the quality of these products are co-determined by local advertising and distribution (retailing) strategies of firms. Especially interesting in this context is that the US is partitioned in more or less discrete population centers across which there is little consumer arbitrage. ${ }^{2}$ This allows for branding strategies to be local. The next section considers a model in which 2 firms can control quality perceptions locally.

\section{Model}

\subsection{Demand}

Utility I use an address model of consumer demand. In this model, consumers $h$ are characterized by a position $\mathbf{z}_{h}$ in a $K$-dimensional attribute space in $\mathbb{R}^{K}$. Consumers' ideal points $\mathbf{z}_{h}$ are not observed by the firm, but their distribution across $h$ is known. Products $i=1,2$ are defined by a known address $\mathbf{z}_{i} \in \mathbb{R}^{K}$ in the attribute space. Consumers $h$ have a quadratic disutility for distance between ideal points $\mathbf{z}_{h}$ and the location of products $\mathbf{z}_{i}$ (d'Aspremont, Gabszewicz, and Thisse 1979). Utility for brand $i$ by household $h=1, \ldots, N_{m}$ in market $m$ is specified by

$$
V_{i h m}=Y_{h}+a_{i m}-p_{i m}-\frac{\mu}{2} \sum_{k=1}^{K}\left(z_{h}^{k}-z_{i}^{k}\right)^{2},
$$

where $Y_{h}$ is income of household $h$. The local quality attribute $a_{i m}$ is a quality perception that is influenced by positioning in the distribution and communication channel and is controllable at the market level. $p_{i m}$ is the price of the product in market $m$. The scalar $\mu$ measures the consumer's disutility of products being far away from his ideal point.

Quality perceptions As discussed previously, quality perceptions are driven by local advertising or shelf-space allocations by retailers. Alternatively, the quality perceptions $a_{i m}$ can capture local

\footnotetext{
${ }^{2}$ In other words, it is generally too expensive for consumers to travel across advertising cells when buying supermarket products. Observationally, this is equivalent to the constraint that consumers are treated as immobile.
} 
versions of the same product. For instance, services in the airline industry are spatially versioned, with individual firms offering more travel flexibility in some regions than in others (see e.g., Karnani and Wernerfelt 1985). However, in the context of CPG, I focus on advantages in quality perceptions of the same product.

Brand positions in the physical attribute space In addition to the quality perceptions $a_{i m}$, I assume that there is one physical attribute $z_{i}^{k}(K=1)$. This attribute is common to all consumers in a market. To rule out a demand-focused explanation of asymmetries, I initially assume that the location of products and consumers is symmetric around zero. Owing to the presence of the multiplier $\mu$, it can be assumed without loss in generality that the position of brand 1 is given by $-\frac{1}{2}$ and of brand 2 by $+\frac{1}{2}$. These brands could alternate positions across markets without affecting the results, hence as above, in principle the model admits products to be geographically versioned.

Location of consumers ideal points in attribute space The consumer ideal points $z_{h} \in \mathbb{R}$ represent the idiosyncratic component of utility. I assume the logistic density for the location of consumers

$$
g(z)=\frac{\exp -z}{(1+\exp -z)^{2}}, z \in \mathbb{R}^{1} .
$$

Expected demand Consumers choose that alternative that maximizes their utility. Expected demand of product $i$ for $N_{m}$ consumers in market $m$ is thus obtained by integrating the utility equation (1) over the support of product $i$ using the consumer density of equation (2). Given the formulation of the utility function the components $Y_{h}$ and $z_{h}^{2}$, do not affect choice (they are common to all alternatives). Given the symmetric positions, the utility component $z_{i}^{2}(i=1,2)$ also drops out of the utility comparisons. What remains is the interaction $z_{h} z_{i}$ of the location of consumers and products. Thus the location of the consumers enters the utility comparison as a linear term, and hence demand is given by a logit model.

$$
\begin{aligned}
s_{i m} & =N_{m} \operatorname{Pr}\left(V_{i}(h, m) \geq V_{j}(h, m)\right) \\
& =N_{m} \frac{\exp \left[\left(a_{i m}-p_{i m}\right) / \mu\right]}{\sum_{\forall j} \exp \left[\left(a_{j m}-p_{j m}\right) / \mu\right]}, i, j=1,2
\end{aligned}
$$

For convenience and because its role turns out to be largely passive, markets are all of equal size and total market size is normalized such that $N_{m}=1$.

The logit demand formulation has broad appeal in both theoretical (e.g., Anderson, de Palma, and Thisse 1992), as well as empirical work (e.g., Berry, Levinsohn, and Pakes 1995). It is noted that with a uniform distribution for $g(z)$, a model obtains that can be seen as a duopoly version of the Mussa-Rosen model. The results of our analysis generalize to this model. 
Because I initially wish to separate margin and multi-market contact effects from demand expansion, the model used here does not account for an outside good. This may be justified by realizing that for mature categories such as coffee, Mexican salsas, and alike, demand expansion in response to price changes is small (Nijs et al 2002). Nonetheless, it is desirable to explore the robustness of the main results to the introduction of an outside good. After establishing several results with the standard model, these results will be shown to generalize to the case of demand with an outside good.

\subsection{Supply}

Marginal $\operatorname{costs} c_{i m}$ are assumed to be constant and not dependent on perceived quality. This expresses the idea that the cost of creating quality perceptions through advertising and/or distribution is fixed with respect to quantity. Investments in perceived quality are denoted $K\left(a_{i m}\right)$ and may depend on $a_{i m}$. This fixed cost assumption is consistent with the use of brand advertising, slotting allowances, pay-to-stay fees, etc, intended to increase the quality perceptions of the brand. For discussions and similar assumptions see Sutton (1991), and Shaked and Sutton (1989).

\section{Analysis}

\subsection{Perceived quality and prices.}

Of initial interest is how perceived quality, $a_{i m}$, affects prices, $p_{i m}$, and profits, $\pi_{i m}$. In this section, firms compete by first simultaneously deciding how much to invest in quality perceptions $a_{i m}$. Conditional on these choices, firms next simultaneously set prices. Marginal cost $c_{i m}$ and fixed cost $K_{i m}$ are initially quality-independent. Thus, for now, firms can increase perceived quality at no additional cost. Later this assumption will be relaxed.

The profit function for brand $i$ in market $m$ is $\pi_{i m}=\left(p_{i m}-c_{i m}\right) \cdot s_{i m}-K_{i m}$. Given the sequence of decisions, prices are solved first. Caplin and Nalebuff (1991) have shown that a unique BertrandNash equilibrium in prices exists for the demand system in equation (3). The first order condition (f.o.c.) for firm $i$ is equal to

$$
\frac{d \pi_{i m}}{d p_{i m}}=\left(p_{i m}-c_{i m}\right) \cdot s_{i m}^{\prime}+s_{i m}=0
$$

From this, the implicit equation for the prices of interest is

$$
p_{i m}^{*}-c_{i m}=\frac{\mu}{1-s_{i m}}, i=1,2
$$


These price equations are implicit because the right-hand side of the expression for the markup contains prices $p_{i m}$, and perceived quality $a_{i m}$ (through $s_{i m}$ ). Using the last equation to solve for $s_{i m}$ and substituting in the profit function gives that at optimal prices

$$
\pi_{i m}^{*}=p_{i m}^{*}-c_{i m}-\mu-K_{i m}
$$

Define the local perceived quality gap as $a_{m} \equiv a_{1 m}-a_{2 m}$. Two useful dependencies of local prices (and profits, given the last equation) on this quality gap are:

\section{Proposition 1 (Optimal Prices)}

1. The price of brand 1 increases and that of brand 2 decreases in $a_{m}$.

2. The price increase (decrease) is never larger than the increase in the perceived quality differential, i.e.,

$$
0<\frac{d p_{1 m}^{*}}{d a_{m}}<1, \text { and }-1<\frac{d p_{2 m}^{*}}{d a_{m}}<0
$$

\section{Proof: see appendix A}

Thus, the price for either brand increases as its perceived quality advantage over the other brand widens. However, neither brand will adjust its price in equal measure to improvements in perceived quality. Consumers get at least part of the utility stemming from the perceived quality improvement. For a related result, see Anderson, de Palma and Thisse (1992), and Anderson and de Palma (2001). The next proposition provides the basis for the two main results in the paper.

Proposition 2 (Perceived quality) Prices and profits are convex in the perceived quality gap, $a_{m}$.

\section{Proof: see appendix A}

Namely, first, as the perceived quality gap between two brands widens, the marginal effect of $a_{m}$ on prices and profits increases. ${ }^{3}$ Proposition 2 therefore implies that low perceived quality brands are less impacted by an increase in perceived quality, than high perceived quality brands are impacted by a comparative decrease. As a consequence, the latter is willing to pay more for sustaining a perceived quality gap than the former is willing to pay for closing it. This creates asymmetries in the market.

Second, in the case of multiple markets, firms can set $a_{i m}$ in each market. By Jensen's inequality, the convexity result then implies that two firms, competing on $M$ markets, would prefer to have

\footnotetext{
${ }^{3}$ The result is not specific to the logit demand function. A linear demand function is obtained by replacing equation (2) with $g(z)=1, z=[-1 / 2, . ., 1 / 2]$. Then, profits at optimal prices can be shown to equal $\pi_{1}=\frac{1}{18} \frac{\left(3 \mu+a_{m}\right)^{2}}{\mu}-K\left(a_{1 m}\right)$ and $\pi_{2}=\frac{1}{18} \frac{\left(3 \mu-a_{m}\right)^{2}}{\mu}-K\left(a_{2 m}\right)$, with $a_{m}=a_{1 m}-a_{2 m}$. From this formulation, it is clear that the proposition replicates.
} 
a distribution of market-specific quality gaps $a_{m}$ over an average vertical positioning difference of $\bar{a}=\frac{1}{M} \sum a_{m}$ in each market.

Before showing that these arguments can produce stable market outcomes, it is useful to analyze the interaction of horizontal differentiation $\mu$ and vertical differentiation $a_{m}$. It was already shown in proposition 1 that profits are increasing in the size of the local quality advantage $a_{m}$. The next proposition makes the point that as products become more similar, profits of the quality leader increase more in local quality advantages but the profits of the low quality player decrease less in local quality disadvantages.

\section{Proposition 3 (Interaction)}

The total effect of quality on profits decreases in the degree of horizontal differentiation, i.e.,

$$
\frac{d}{d \mu}\left(\frac{d \pi_{i m}}{d a_{m}}\right)<0
$$

Proof: see appendix A

To understand the interaction between horizontal and vertical differentiation in this model, it is useful to consider two extreme cases. First, for $\mu$ very small (limiting to 0), the firm that has the higher perceived quality will price this advantage almost completely to the market and still capture all demand. Thus, $\frac{d \pi_{i m}}{d a_{m}}$ approaches 1 for the firm that has the quality advantage. For the firm that has the lower perceived quality and zero demand, increasing the quality disadvantage has no consequence, i.e., $\frac{d \pi_{i m}}{d a_{m}}$ approaches 0 for the firm that lags in quality. Thus when products are similar, the lagging firm has no incentive to invest in quality, whereas the leading firm has a positive pay-off to investments in quality.

For $\mu>0$, there are customers to whom the lower quality product is preferred because it is closer to their ideal points. The leading firm now sets prices taking into account not only the perceived quality advantage but also the adverse quantity effect of pricing too high. The marginal effect of a quality improvement on prices and profits is therefore less than 1. For the lagging firm, the effect of a quality improvement by the leading firms is no longer 0 but is negative. I subsequently show (in proposition 4 below) that in the limit, as $\mu \rightarrow \infty$, the marginal effect of a quality improvement on profits of the leading firm is $\frac{1}{3}$ and for the lagging firm it is the exact opposite $-\frac{1}{3}$. Proposition 3 therefore implies that as $\mu$ increases from 0 to infinity, the marginal effect of perceived quality improvements on profits continuously decreases from 1 to $1 / 3$ in the case of the higher quality brand and from 0 to $-1 / 3$ in the case of the lower quality brand. 
In words, when there is little horizontal differentiation, the incentives to maintain/dissolve differences in perceived quality are very asymmetric for the high vs. the low quality player. In contrast, if there is sufficient horizontal differentiation, then the player with the high perceived quality has the same incentive to maintain the quality gap as the low perceived quality player has to close it. It is this contingency that drives the results in section 5 .

\subsection{The case of a single market and free quality improvements}

Before showing the existence of asymmetric equilibria and their dependence on $\mu$, I first present a benchmark result against which to compare results later. In this benchmark case, cost $K$ remains independent of perceived quality. To simplify the analysis, I make the additional assumption that the response function to investments in quality perceptions is sufficiently S-shaped or convex that firms would not consider other levels of perceived quality than $a_{\ell}$ or $a_{h}$, with $a_{h}>a_{\ell} \cdot{ }^{4}$ Firms first set perceived quality $a_{i m}$ simultaneously and subsequently choose prices. Then, both firms will end up positioning at $a_{h}$.

Proposition 4 (Single Market) In the single market equilibrium both firms position at $a_{h}$ and charge a price of $c+2 \mu$. Profits are equal to $\mu-K$.

Proof: see appendix A

That is to say, given proposition 1 both brands choose to set perceived quality high. As a consequence, both brands set equal prices and have equal market shares. The role of $\mu$ in this case is that, as expected, profits and prices rise in the degree of horizontal differentiation. ${ }^{5}$ In other words, if horizontal differentiation is effectively absent, price competition will drive margins to zero.

I now consider how the above result can be avoided as a function of several realities of brand competition in packaged goods industries: (i) absence of strong horizontal differentiation, (ii) quality perceptions are costly to obtain, (iii) firms meet in multiple geographic markets and may have a first mover advantage in all or part of these markets.

\footnotetext{
${ }^{4}$ This is equivalent to assuming that the response function to investments in perceived quality (through, e.g., advertising or distribution) is sufficiently convex or S-shaped. The S-shape assumption is commonly used in share response to advertising (Little 1979), whereas the relation between ACV distribution and share is empirically convex (Reibstein and Farris 1995).

${ }^{5}$ Soberman (2005) shows however that in a single market, if consumers differ with respect to their awareness of products, the monotonicity of profits in differentiation may not hold.
} 


\section{Local asymmetries from competition in costly quality percep- tions}

\subsection{Prices}

Now, consider a single market (drop the subscript $m$ momentarily) and fixed costs $K\left(a_{i}\right)$ that depend on the level of perceived quality $a_{i}$. As stated in the introduction, such quality-dependent fixed cost can be thought of as investments in advertising or distribution. I maintain the assumption that consumer response to these variables is S-shaped or convex to the extent that only two levels of $a_{i m}$, denoted $a_{h}$ and $a_{\ell}$ (with $a_{h}>a_{\ell}$ ) need to be considered. It is assumed that $K\left(a_{h}\right) \geq K\left(a_{\ell}\right)$ if $a_{h}>a_{\ell}$. Again, manufacturers first set positioning, and then simultaneously decide on prices. Demand for brand $i$ is given by equation (3). In a single market context, profit for each of the manufacturing firms is equal to

$$
\pi_{i}=s_{i}\left(p_{i}-c\right)-K\left(a_{i}\right)
$$

From the first-order conditions, prices are equal to

$$
p_{i}^{*}=c+\frac{\mu}{1-s_{i}}
$$

whereas profits at these optimal prices can be expressed as

$$
\pi_{i}^{*}=\frac{\mu s_{i}}{1-s_{i}}-K\left(a_{i}\right)
$$

\subsection{Perceived quality}

Asymmetric positioning Consider first the case where brand 1 is positioned at $a_{h}$ while brand 2 is positioned at $a_{\ell}$. When is this an equilibrium? Profit at the optimal prices computed above is for brand 1 equal to $\pi_{1}^{*}=\mu \Phi-K\left(a_{h}\right)$, with $\Phi=\frac{s_{1}}{1-s_{1}}$. Thus $\Phi$ is the ratio of the demand for the high quality brand over the low quality brand. It is dependent on the perceived quality gap $a_{1}-a_{2}$ and on the price gap $p_{1}-p_{2}$ between firms in a market. Proposition 1 implies that $\Phi>1$, because the brands are priced such that consumers receive at least a part of the utility stemming from quality improvements. Suppose firm 1 considers repositioning to $a_{\ell}$. If so, it splits the market evenly with firm 2 (which is also positioned at $a_{\ell}$ ) and, from equation 9 , its profits would equal $\mu-K\left(a_{\ell}\right)$. Thus, firm 1 will not reposition to $a_{\ell}$ as long as $\mu \Phi-K\left(a_{h}\right)>\mu-K\left(a_{\ell}\right)$. 
Firm 2, positioned "low," will not reposition if the payoff of sustaining $a_{\ell}$ is larger than that of repositioning to $a_{h}$. This implies that $\mu \Phi^{-1}-K\left(a_{\ell}\right)>\mu-K\left(a_{h}\right)$. By combining these results, neither firm has an incentive to deviate from asymmetric positioning as long as

$$
\mu\left(1-\Phi^{-1}\right)<\Delta K<\mu(\Phi-1)
$$

with $\Delta K \equiv K\left(a_{h}\right)-K\left(a_{\ell}\right)$. Note that $\mu\left(1-\Phi^{-1}\right)<\mu(\Phi-1)$ because $\Phi>1$. Thus, there always exist a pair of fixed costs $\left[K\left(a_{h}\right), K\left(a_{\ell}\right)\right]$ that make asymmetric positioning an equilibrium.

Symmetric positioning With symmetric positioning at $a_{\ell}$, the profits for both firms are $\pi_{i}^{*}=\mu-K\left(a_{\ell}\right)$. If either firm repositions to $a_{h}$, profits of that firm will be $\mu \Phi-K\left(a_{h}\right)$. Thus, if $\Delta K>\mu(\Phi-1)$, then repositioning will not occur and a symmetric equilibrium with both firms positioned at $a_{\ell}$ holds. Following similar logic, a symmetric equilibrium at $a_{h}$ is obtained when it is not profitable for either firm to reposition to $a_{\ell}$. This happens when $\Delta K<\mu\left(1-\Phi^{-1}\right)$. In sum, if it is cheap enough to position at $a_{h}$, all firms will do so, whereas if it is too expensive then neither firm will. However, over an intermediate range of cost of investing in quality, one brand will position at $a_{h}$ and the other at $a_{\ell}$.

The following proposition formalizes these results.

\section{Proposition 5 (Costly quality perceptions - single market)}

1. (a) Both brands are positioned symmetrically at $a_{h}$, if $\Delta K<\mu\left(1-\Phi^{-1}\right)$.

(b) Brands are positioned asymmetrically with one at $a_{h}$ and the other at $a_{\ell}$, if $\mu\left(1-\Phi^{-1}\right) \leq$ $\Delta K \leq \mu(\Phi-1)$.

(c) Both brands are positioned symmetrically at $a_{\ell}$ if $\Delta K>\mu(\Phi-1)$.

2. (a) The range of cost differentials $\Delta K$ over which asymmetric positioning is the only equilibrium decreases monotonically in $\mu$,

(b) with the following limiting bounds

$$
\begin{aligned}
\lim _{\mu \downarrow 0}\left\{\mu\left(1-\Phi^{-1}\right), \mu(\Phi-1)\right\} & =\left\{0, a_{h}-a_{\ell}\right\} \\
\lim _{\mu \rightarrow \infty}\left\{\mu\left(1-\Phi^{-1}\right), \mu(\Phi-1)\right\} & =\left\{\left(a_{h}-a_{\ell}\right) / 3,\left(a_{h}-a_{\ell}\right) / 3\right\}
\end{aligned}
$$

Proof: see appendix A

The fixed costs $K(a)$ can sustain an asymmetric equilibrium between firms in a single market. The asymmetry is due to the differences in returns on investment in perceived quality between the high quality and the low quality player discussed in section 4 .

The bounds $\left\{\mu\left(1-\Phi^{-1}\right), \mu(\Phi-1)\right\}$ are the limits on the set of all cost differentials $\Delta K$ for which asymmetric market shares will result. The width of this range can thus be interpreted as a 
measure of the generality with which an arbitrary cost function $K(a), a>0$, obeys $\mu\left(1-\Phi^{-1}\right) \leq$ $\Delta K \leq \mu(\Phi-1)$. If it is wide, any cost differential will support an asymmetric market outcome as the only equilibrium outcome. The proposition states this is exactly what happens when products are similar. In the limit, when products are objectively the same, $\mu \downarrow 0$, the range is widest. Conversely, if horizontal differentiation is more substantial, the cost range will narrow, reducing the support for asymmetric equilibria, in the limit eliminating it completely.

The proposition above shows the emergence of asymmetric market shares, but makes no prediction about who will choose $a_{h}$ and who will choose $a_{\ell}$. Allowing firms to set perceived quality sequentially solves this indeterminacy. The next proposition below makes the point that when asymmetric equilibria occur, the first mover will always choose the higher quality perception $a_{h}$ and the follower who will take $a_{\ell}$. More completely, the following cases hold.

\section{Proposition 6 (Sequential moves)}

1. (a) If $\Delta K<\mu\left(1-\Phi^{-1}\right)$, both firms will choose $a_{h}$ and moving first has no impact on equilibrium outcomes

(b) If $\mu\left(1-\Phi^{-1}\right) \leq \Delta K \leq \mu(\Phi-1)$ the first mover in quality will set perceived quality at $a_{h}$ and the late mover will set perceived quality at $a_{\ell}$.

(c) $\Delta K>\mu(\Phi-1)$, both firms will choose $a_{\ell}$ and moving first has no impact on equilibrium outcomes

Proof: see appendix A

\subsection{Graphical interpretation and discussion}

I find that when otherwise undifferentiated firms compete on perceived quality, vertical differentiation emerges endogenously. Figure 2(a) illustrates this finding from the result that profits are convex in differences in perceived quality $a_{1}-a_{2}$. In this example, if firm 1 is positioned at $a_{1}=a_{h}$, and firm 2 is positioned at $a_{\ell}$, then the profit for firm 1 is equal to $C(=\mu \Phi)$. On the other hand, profits for

firm 2 are $A\left(=\mu \Phi^{-1}\right)$. If both firms have the same level of quality then both of their profits are equal to $B(=\mu)$. Therefore, the maximum firm 2 is willing to pay for repositioning to $a_{h}$ is the difference in profits $B-A$, whereas the maximum firm 1 is willing to pay to remain at $a_{h}$ is equal to $C-B$. Therefore, as long as the cost to produce $a_{h}$ is between $B-A$ and $C-B$, different quality choices are the equilibrium. Proposition 4 implies that the difference between the intervals $C-B$ and $B-A$, i.e., $C+A-2 B$ decreases in $\mu$. 
(a) one market

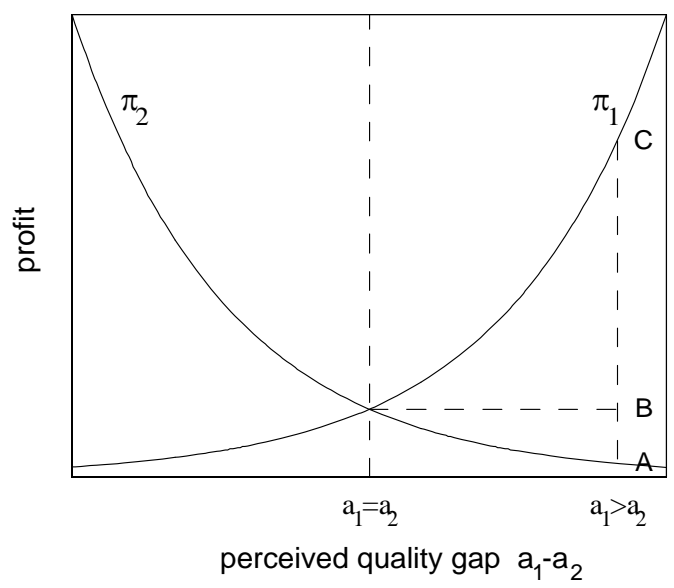

(b) two markets

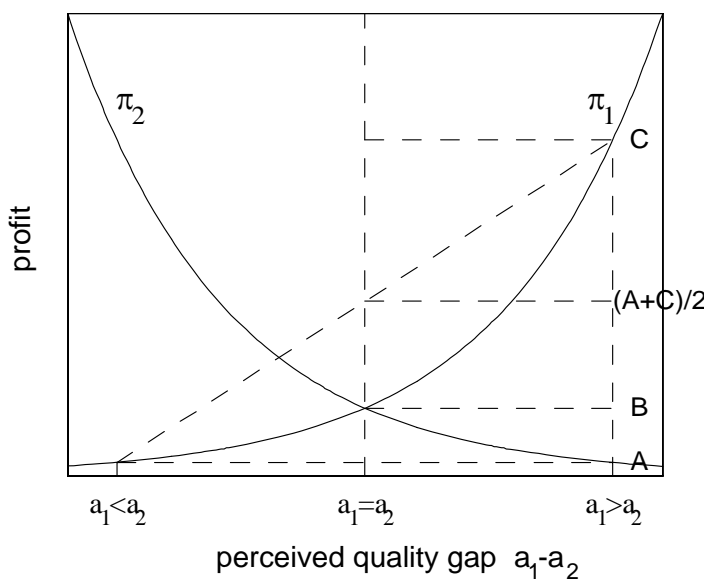

Figure 2: Convexity of profits in quality and asymmetric equilibria

Thus, the asymmetric distribution of brand shares for objectively similar products within a market, can be explained as a single market outcome of competitive investments in perceived quality, e.g., local brand building. The local distribution of perceived quality depends on the primitives in the model: (i) production costs $(K(a))$, (ii) the degree of horizontal product differentiation $\mu$, (iii) and order of entry. My results can be summarized as follows:

Quality costs Because of an assumed S-shaped response in $a_{i m}$, the results in this section hold with an arbitrary cost function across 2 perceived quality levels. Yarrow (1989) considered the specific case of $K(a)=\exp (a)$, and also finds that local asymmetric quality choices may emerge. He does not consider the geographic patterns in CPG brand competition, the effect of sequential quality choices, or as we do momentarily, multimarket contact.

Horizontal differentiation The emergence of asymmetric choices of perceived quality is more general when goods are horizontally undifferentiated (the cost interval $\left\{\mu\left(1-\Phi^{-1}\right), \mu(\Phi-1)\right\}$ decreases monotonically in $\mu) .{ }^{6}$ The intuition behind this dependence on $\mu$ is that when goods are undifferentiated and quality perceptions are expensive to obtain, there is only "room" for one high quality player in the market. The low quality player realizes there is nothing to gain from imitating the high quality player. In CPG industries, where demand expansion is small compared to gains from substitution, copying the high quality player would result in lower demand and lower margins than

\footnotetext{
${ }^{6}$ This result holds also when equation 2 is replaced by $g(z)=1, z=[-1 / 2, \ldots,+1 / 2]$. In that case demand is linear and the region over which asymmetric choices of quality hold is equal to, $\frac{\Delta a}{3}-\frac{(\Delta a)^{2}}{18 \mu}<\Delta K<\frac{\Delta a}{3}+\frac{(\Delta a)^{2}}{18 \mu}$. Clearly, this region widens (monotonically) as $\mu$ becomes smaller.
} 
the high quality player currently has. These beliefs about expected profits from quality improvements effectively turn the investment in perceived quality by the first mover into a "barrier to copy."

Order of entry When firms move sequentially in setting quality perceptions, the asymmetric equilibria are characterized by the first mover taking the higher quality positioning. In Moorthy (1988), the asymmetric equilibrium is also interpreted as a possible advantage of the first entrant. However, in my case, a first mover advantage in perceived quality only emerges strategically when $\mu$ is small enough, i.e., only when products that are horizontally similar. In other cases, perceptual differences will be absent or competed away. Interestingly, Golder and Tellis (1993) report that first mover advantages are larger and more persistent for non-durable products than for durable products.

Finally, in CPG industries, the technology is in place to control perceived quality, retail support, or brand awareness at a local level. In addition, there is little to no arbitrage across local markets at the state or even metropolitan level. Hence, as a consequence of CPG products often being objectively similar and different firms having a first mover in different regions (Bronnenberg, Dhar and Dubé, 2005), the central results in this section provide a theoretical basis for why cross-market variability in shares emerges and is stable.

\section{Sustaining historical asymmetries through multi-market contact}

\subsection{Sustaining a multimarket equilibrium in the most conservative case: zero cost of repositioning}

An independent but reinforcing argument for the results in the previous section arises from the practice, common in the domestic CPG sector, that firms meet each other in multiple markets. This creates the possibility of coordination between firms. To provide an analytic foundation for a discussion about collusive multi-market equilibria, the base-scenario analyzed in this section is one of two firms, two markets, and again two levels of perceived quality: high $\left(a_{h}\right)$ and low $\left(a_{\ell}\right)$. Firms can increase perceived quality from low to high at no cost. This constitutes the cost scenario where firms are most tempted in the short run to choose a high perceived quality level $a_{h}$. Indeed, the idea behind this assumption is that if asymmetries are sustainable in a multimarket setting, even if it is free to improve quality, they will surely be sustainable if it is costly to improve from a low to a high perceived quality brand. Firms each maximize multi-market profits by choosing positioning $a_{i m}$ first and setting prices $p_{i m}$ next. 
Each firm is endowed with one market in which it is the sole provider of a high perceived quality product and one market in which it is the sole provider of a lower perceived quality product. This pre-existing condition is exogenous to the analysis. The subsequent analysis therefore applies to the local advantages in the previous section, but also to local advantages whose origins are fleeting. As is usual in a multi-market contact framework, firms are allowed to interact repeatedly in an infinite horizon game (Bernheim and Whinston 1990). ${ }^{7}$

Figure 2(b) shows the profit functions $\pi$ of firms 1 and 2 and in a two-market scenario. In the market where firm 1 is positioned at $a_{h}$ (and firm 2 at $a_{\ell}$ ) it makes a profit of $C$. In the other market it is positioned at $a_{\ell}$ (and firm 2 at $a_{h}$ ). Firm 1 makes profits of $A$ in this market. However, if it is free to do so, it will be tempted to improve quality in the market where it is lagging, because this increases its current multimarket profit (i.e., $B+C>A+C$ ). I assume that the consequence of not colluding is to remain positioned symmetrically in both markets at $a_{h}$ forever. First, this is optimal in the short run, if $a_{h}$ comes at no cost. Second, this is consistent with the idea that when firms have eliminated the perceived quality gap between two brands, such a gap is not easily recreated. In sum, firms in this argument are represented as trading off an immediate profit improvement in their lagging market from $A$ to $B$ with future profit deterioration in strong markets from $C$ to $B$.

Let $\pi_{1}^{*}$ denote multimarket profits with asymmetric positioning, i.e., $\pi_{1}^{*}=A+C=\left(\Phi^{-1}+\Phi\right) \mu-$ $2 K$ (with $\Phi$ as defined before). The payoff for a one-time deviation for firm 1 is $\pi_{1}^{d}=B+C=$ $(1+\Phi) \mu-2 K$, which is always larger than $\pi_{1}^{*}$. After firm 2 observes that it is attacked in its best market by firm 1 , next period it optimally repositions in market 1 from $a_{\ell}$ to $a_{h}$. The payoff for both firms is now equal to $\pi_{i}^{0}=B+B=2 \mu-2 K$ forever. The following proposition holds:

\section{Proposition 7 (multimarket contact)}

1. If both firms each have a market in which they lead, they both make more profits than if they share each market equally.

2. The minimum discount factor that resists short term deviation and sustains the local asymmetries is equal to the ratio of each firm's smaller and larger market share, i.e., $\delta^{*}=\Phi^{-1}$

3. The minimum discount factor ("future valuation") needed to sustain local asymmetries ( $\left.\delta^{*}\right)$ increases monotonically from 0 with the degree of product differentiation.

Proof: see appendix A

\footnotetext{
${ }^{7}$ Comparisons to the single period single market game in the previous section are thus not immediate. However, unless consumers accept the idea of each firm taking periodic turns at being the "high-quality" player, a single market repeated game will result in the same equilibrium as the single period game.
} 
The first part of the proposition states that $\pi_{i}^{*}>\pi_{i}^{0}$, i.e., that there is always a profit incentive to sustain spatial concentration. As stated before, this result is implied by proposition 2. Indeed, with asymmetric positioning for both firms in both markets, the perceived quality gap in market 1 is $a_{1}=a_{h}-a_{\ell}$, whereas in market 2 it is $-a_{1}$. The positioning difference when both competitors position at $a_{h}$ is equal to 0 in both markets. It follows from the proposition that for both firms $\pi\left(a_{1}\right)+\pi\left(-a_{1}\right)>2 \pi(0)$.

The second part of the proposition notes that in order for the multimarket collusion to hold, the discount rate has to exceed $\Phi^{-1}$. Given that $\Phi>1$ by construction, $0<\delta^{*}<1$. As a matter of interpretation, the more asymmetric existing outputs are, the less forward looking managers need to be to sustain them.

The third part of the proposition is based on the result that $\partial \delta^{*} / \partial \mu>0$. This result implies that as markets are less and less differentiated, even myopic managers will resist the temptation to reposition to gain higher perceived quality. Figure 2(b) helps explain that this is for 2 reasons. First, the post-deviation drop in profits $C-B$ from competing head-to-head is larger with less product differentiation, i.e., the long term punishment increases as $\mu$ decreases. Second, the short term incentive to deviate $B-A$ goes to zero as $\mu$ becomes smaller, i.e., the short term benefit of deviation decreases.

The interpretation of this proposition is that once a CPG industry has a geographic distribution of leading brands, these leading brands have an incentive not to fight too hard in the markets where they are lagging for fear of "commoditizing" the market, which would make all firms worse off.

\subsection{Elaborations and generalizations}

I now discuss a number of elaborations to illustrate that the multimarket result is robust to alternative assumptions. The proofs for these elaborations are available upon request from the author.

The presence of an outside good The previous analysis generated an unconditional result because it isolated one specific aspect of multi-market competition, namely, that spatial concentration creates local market power for both firms. However, it is possible that positioning both products at $a_{h}$ raises category-demand. To investigate the effect of demand expansion on the monopoly power argument, I investigate positioning and pricing decisions in the presence of an outside good. Demand 


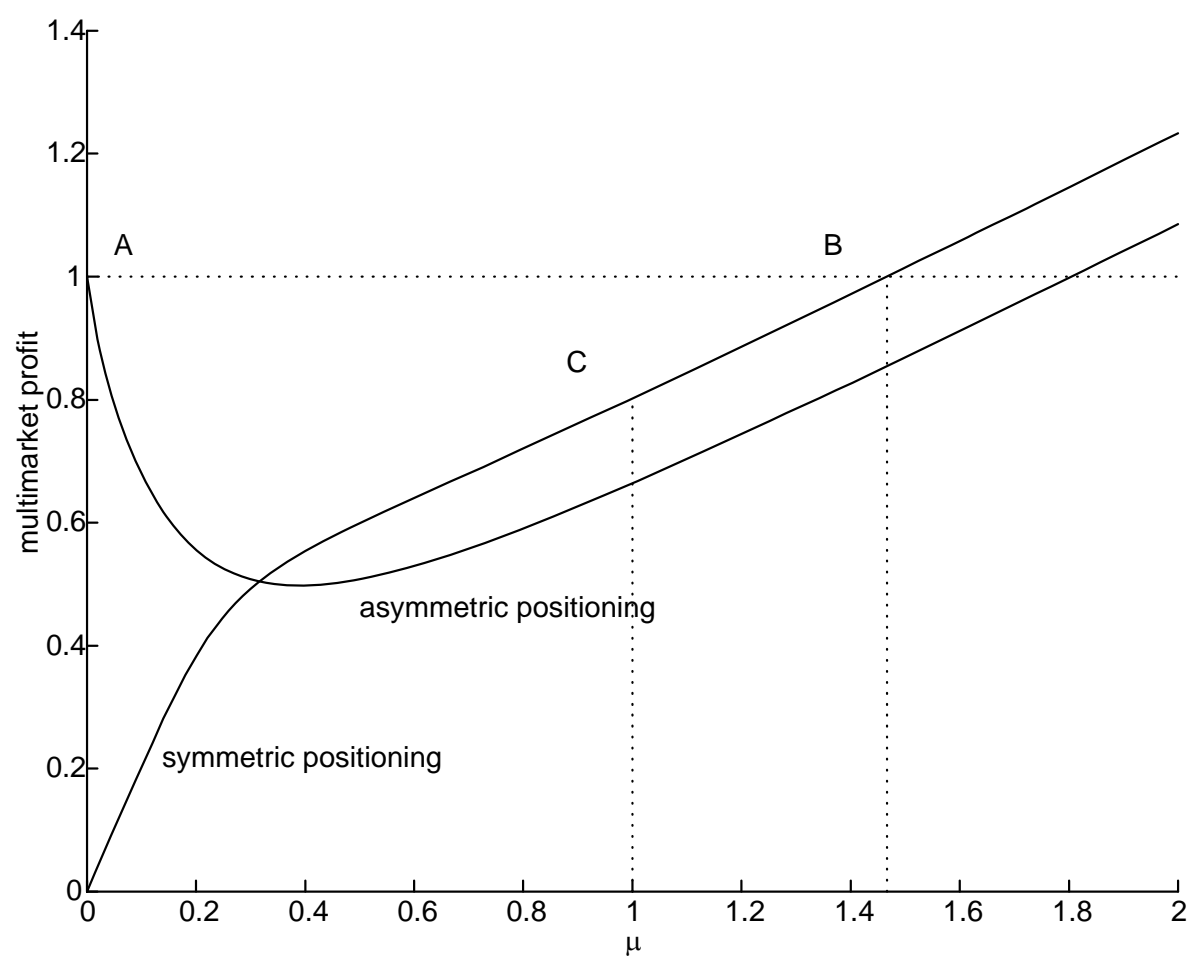

Figure 3: Multimarket profits with symmetric and with asymmetric positioning

is now given by

$$
s_{i m}=N_{m} \cdot \frac{\exp \left[\left(a_{i m}-p_{i m}\right) / \mu\right]}{\exp \left[\left(a_{1 m}-p_{1 m}\right) / \mu\right]+\exp \left[\left(a_{2 m}-p_{2 m}\right) / \mu\right]+\exp \left[V_{0} / \mu\right]}, i=1,2, m=1,2,
$$

where $V_{0}$ is the value of the outside good. As before, set $N_{m}=1$ in both markets.

Equation (5) still describes optimal prices given positioning. I find that as long as demand expansion from both products positioning at $a_{h}$ is not too large, firms are motivated to sustain a geographic distribution of asymmetric perceived quality. A similar contingency on $\mu$ is found. The intuition for this is that demand expansion is likely to be small for undifferentiated products. If the products are the same, then increasing the perceived quality of one of them while the other is already of high quality should not affect their cumulative demand appreciably. This is not the case for differentiated goods where increases in perceived quality draw demand that is unique to each product.

To illustrate the main result, consider the following graphs of profits under asymmetric positioning vs. symmetric positioning as a function of $\mu$. Figure 3 shows the multi-market profits at optimal prices when $a_{h}=1, a_{\ell}=0$, and $V_{0}=-1$. The curve labeled "asymmetric positioning" shows the 
sum of profits of dominating in one market but being dominated in the other. The curve labeled "symmetric positioning" shows a firm's multimarket profits when both firms position at $a_{h}$. As is clear from the graph, again, an interesting contingency on $\mu$ emerges. For modest degrees of horizontal differentiation, the profit incentive to sustain asymmetries is present and given sufficient valuation of future profits asymmetric positioning is an equilibrium. However, for stronger horizontal differentiation, due to demand expansion, asymmetric positioning is not as profitable as symmetric positioning at $a_{h}$.

A final aspect of the "asymmetric positioning" profit curve is noteworthy. Profits decrease in the degree of horizontal differentiation, $\mu$, for $\mu$ small enough. Thus, having "intermediate" levels of product differentiation may be less profitable than having no product differentiation at all (see also Klemperer, 1992, who raises a similar point). Point $A$ in Figure 3 shows that profits from asymmetric positioning are 1 when there is no horizontal differentiation, i.e., $\mu=0$. Not until a relatively high degree of horizontal differentiation, $\mu=1.47$, is there a scenario with equal profits (point $B$, which applies to symmetric positioning at $a_{h}$ in both markets).

M-markets For local asymmetries to be sustained in a multimarket environment, I assumed that the firms have 1 market in which they lead and 1 market in which they lag, i.e., that firms are globally equally well off. Consider the case of $M$ markets. In $L$ of these markets firm 1 leads. The following results are now true. First, the profit incentive to sustain local differences in perceived quality remains present even if $L$ is small, as long as $\Phi>L /(M-L)$. This result gives a simple condition under which both firms are better off with local asymmetries than with local symmetries: local demand share in the strong markets needs to be larger than the geographic share of weak markets. This condition is guaranteed for the firm with the lesser amount of weak markets, but it poses a boundary condition on the presence of a profit incentive for the other firm. The firm with the smaller number of "strong" markets therefore has a profit incentive only if the asymmetries are strong enough.

Second, this condition will become true for any $L>0$ as $\mu$ gets smaller. This means that for low levels of horizontal differentiation, $\mu$, firms will sustain market asymmetries, even if they only lead in a small minority markets. The second result states that, in the case of $M$ markets, as was the case for a 2 market duopoly, the profit incentive to sustain asymmetries is more generally present when firms are less horizontally differentiated. Also, this result is implied by proposition 7 that $d \Phi / d \mu<0$. 


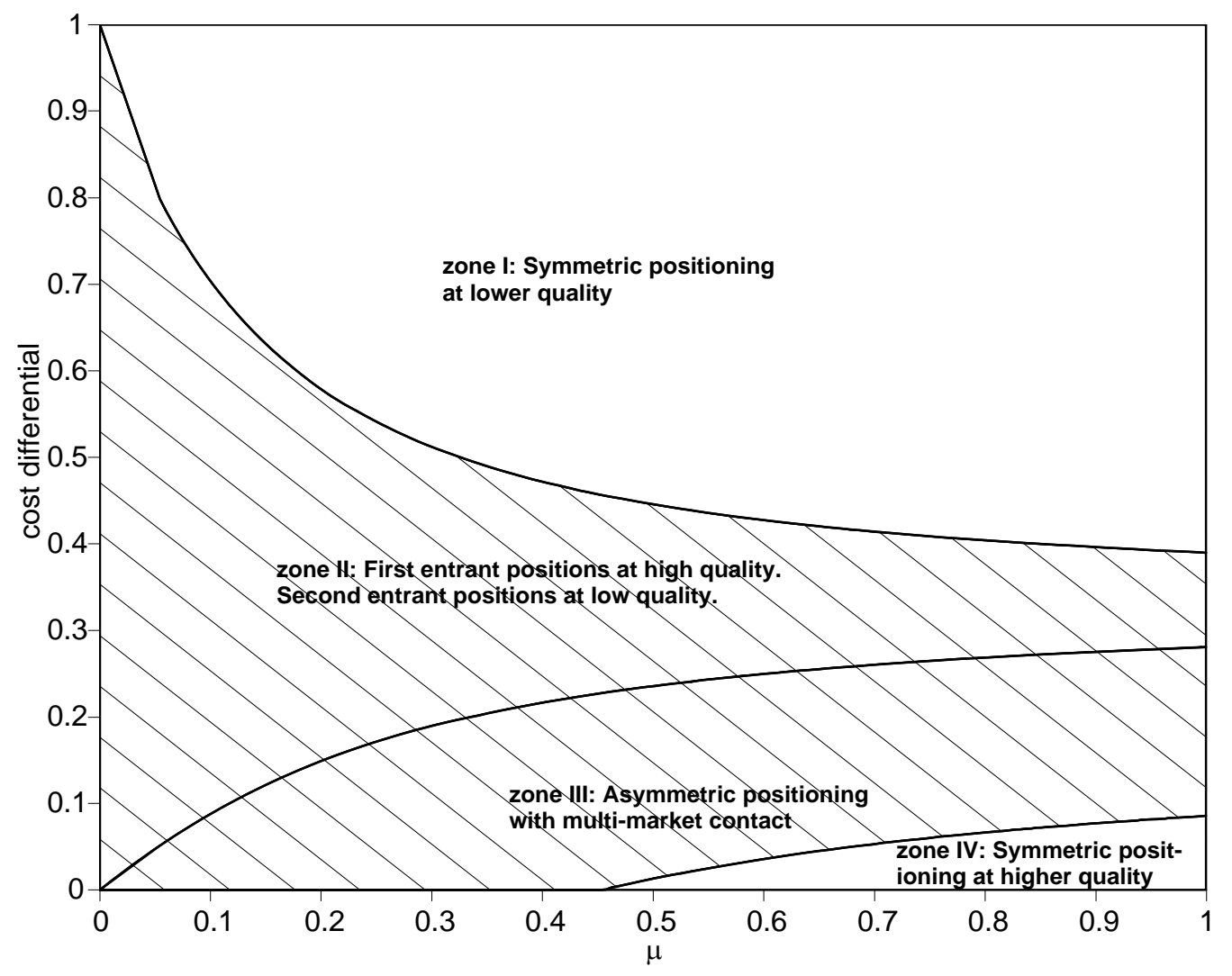

Figure 4: Equilibria for product differentiation $\mu$, and cost differential $\Delta K$.

Costly perceived quality investments

The base scenario in the multimarket case contained the assumption that improvements in perceived quality come at no costs. Relaxing this assumption makes that the argument in this section holds even stronger. That is to say, we obtain the exact same result as before, except that the minimum discount rate at which asymmetric equilibria are sustain decreases even further. Specifically, rather than $\delta^{*}=\Phi^{-1}$ as in proposition 7 ,

$$
\delta^{*}=\frac{1}{\Phi}\left(1-\frac{\Delta K}{\mu\left(1-\Phi^{-1}\right)}\right)
$$

which is always smaller. Indeed, costly investments in perceived quality make attacking expensive and effectively discourage mimicking the high quality player (as was seen in the previous section).

\subsection{Summary}

To summarize the analytical results of the previous sections on single and multimarket equilibria, figure 4 summarizes the results in this paper by outlining the equilibria that exist for alternative 
values of the three variables of our competitive analysis of the CPG industry: (i) the costs of creating local perceived quality $\Delta K$, (ii) the degree of objective horizontal differentiation $\mu$, and (iii) the sequence of choosing quality. The numerical scenario considered here uses $a_{h}=1$ and $a_{\ell}=0 .^{8}$

Zone I outlines the cases where the cost difference between positioning high and low is so large that both products position low in all markets. Because it does not pay to invest in a single market, there is no profit incentive to invest in a multimarket contact framework.

Zone II represents the cases covered in section 5 where a single-market asymmetric equilibrium exists. If competition takes place on two markets, a firm may lead in both markets, in one, or in none, depending on local entry patterns. In this case, if order of entry is spatially dependent (as found in Bronnenberg, Dhar and Dubé 2005) this case covers the emergence of geographic concentration of market share as is seen widely in CPG industries. Incentives to deviate in any single market are absent from all these scenarios. Consequently, deviations in multiple markets are also unprofitable.

Zone III identifies the cases covered in the current section when asymmetric equilibria are sustainable in two markets but not in a single market. Here the cost difference between positioning high or low is so small that in a single market case, all products would position at $a_{h}$. However, in a two-market context, firms prefer to sustain spatial concentration if they value the future enough. Figure 4 was created with $\delta=0.75$. Thus even if firms only value next period's profits at $75 \%$ of current profits, the area over which spatial concentration is sustainable increases very substantially.

Finally, zone IV contains all cases where firms position at $a_{h}$ in all markets. As the firm's value for future profits increases, the fourth zone will diminish (as an example if $\delta=0.90$, zone IV is no longer visible in Figure 4).

Zones II and III combined give all cases where a spatially concentrated market equilibrium may occur. One of the central results of the analysis is that the occurrence of asymmetric equilibria is strongly dependent on horizontal differentiation. Indeed, Figure 4 illustrates once more that sustained asymmetric market shares as in Figure 1 is more likely to happen with undifferentiated than with differentiated goods.

It is noted that the introduction of an outside good does not affect Figure 4 substantively, as long as the outside good is not too large.

\footnotetext{
${ }^{8}$ The discussion does not seem to be affected by other numerical choices for $a_{h}$ and $a_{\ell}$.
} 

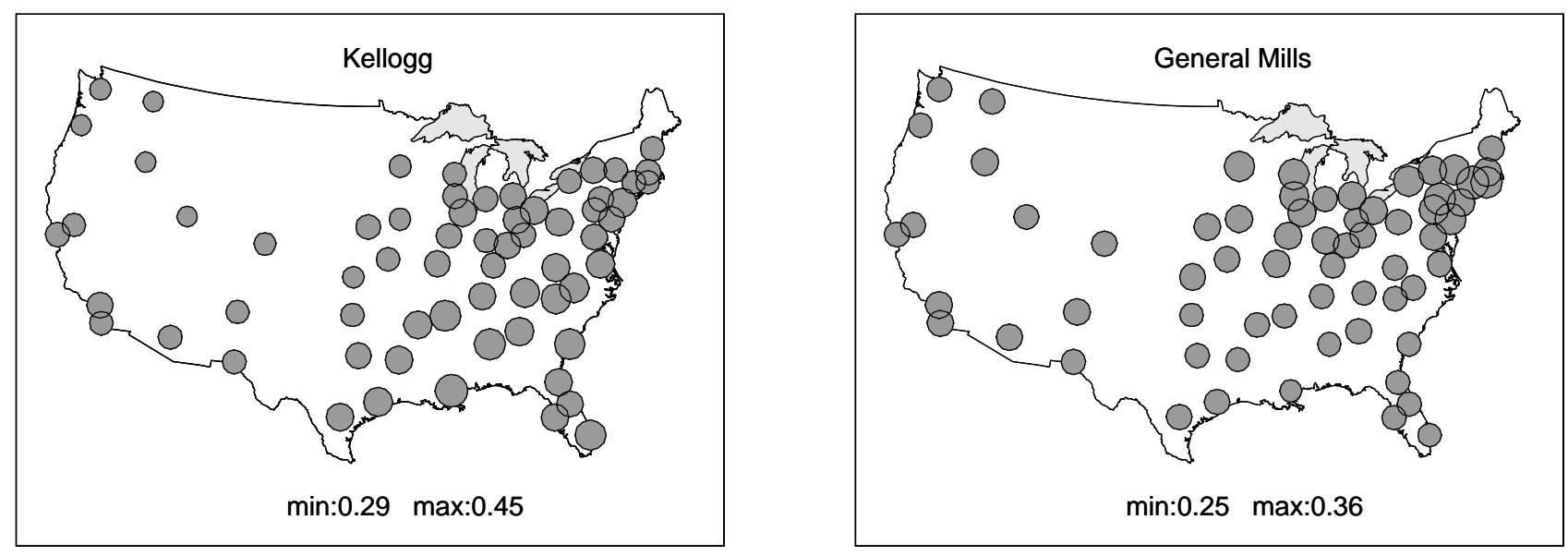

Figure 5: Local market share of two leading manufacturers in cereals

\section{Discussion}

This analysis is motivated by the common existence of locally asymmetric market shares for weakly differentiated national brands in categories such as Mexican salsas. The main result of this paper is that such local asymmetries persist over time especially for undifferentiated consumer goods as illustrated in Figure 1. Conversely, incentives to create and sustain perceived quality differentiation are less strong when products are horizontally differentiated.

Thus, this study predicts that local share asymmetries should not occur to the same extent as Figure 1 in categories with differentiated goods. For discussion purposes, I present one example of such a category: breakfast cereals. Consumers can easily distinguish, say, Kellogg's Corn Flakes from General Mills Cheerios. More broadly, Nevo (2001) observes that the top manufacturers of breakfast cereals differentiate their products.

If the national brands in the cold breakfast cereals category are horizontally more differentiated than the national brands in Mexican salsas, the arguments presented here predict strong variation in local shares in the Mexican salsa but not in the cold cereal industry. If in addition the brands in both industries are roughly symmetric (the national brand pairs are of similar objective quality and all cater to the mass market), the local ratio between the leading brand's share and the second brand's share is predicted to be large in the case of Mexican salsas but close to unity for the breakfast 


\begin{tabular}{|r|c|cc|}
\hline & $\begin{array}{c}\text { mexican salsa } \\
\text { Campbell (Pace) vs. } \\
\text { Frito Lay (Tostitos) }\end{array}$ & $\begin{array}{c}\text { breakfast cereals } \\
\text { Kellogg vs }\end{array}$ & $\begin{array}{c}\text { Corn Flakes vs } \\
\text { General Mills }\end{array}$ \\
Cheerios \\
\hline standard deviation $\left(\log \left(\right.\right.$ share ratio $\left.\left._{m}\right)\right)$ & 0.90 & 0.16 & 0.32 \\
markets with $\left(\frac{\text { leading share }}{m}\right)>2$ & $28 / 64$ & $0 / 65$ & $0 / 65$ \\
lagging share & & & \\
mean $\left(\frac{\text { leading share }}{m}\right)$ & 2.65 & 1.22 & 1.35 \\
\hline
\end{tabular}

Table 1: Differences in spatial variability and asymmetry

cereals. Figures 1 and 5 show that this is indeed what happens. ${ }^{9}$

Table 1 presents three measures of share asymmetry across and within markets for the Mexican salsa and breakfast cereal industries. The first measure is the standard deviation across markets of the log share ratio. It quantifies the variability in share ratios across markets. From Table 1, it is clear that this measure of spatial variability is much larger in the Mexican salsa than in the breakfast cereal industry. The second and third measure quantify share asymmetries within markets. In the competition between Pace and Tostitos, the average size of the local leader is 2.65 that of the second brand. In the competition between Cornflakes and Cheerios, this ratio is 1.35 (only 1.22. in the competition between Kellogg and General Mills). ${ }^{10}$

This example supports the existence of a link between horizontal product differentiation and the sustainability of asymmetric market shares in an industry.

\section{Conclusion}

There are many reasons why competing firms of undifferentiated goods face different initial conditions in a given market, e.g., order-of-entry effects on brand perceptions (e.g., Bronnenberg, Dhar and Dubé 2005) or on shelf-space (Bowman and Gatignon 1990; Robinson and Fornell 1985). These phenomena can lead to initial differences in market shares and profitability. I find that such initial differences can be sustained under conditions commonly observed in CPG industries: the leading national brands sell objectively similar products, order of entry and costly investments in perceived quality are local,

\footnotetext{
${ }^{9}$ The figure for breakfast cereal brands as opposed to manufacturers is very similar to Figure 5.

${ }^{10}$ This measure can be redefined to reflect differences in the national shares of brands. That is, if the national brands are not symmetric, we use within market asymmetries adjusted for the national asymmetry in share. These adjustments do not materially change the example in the table.
} 
and firms meet in multiple markets. Even after the original reasons for the asymmetries that arise from such initial conditions vanish, this paper has shown that local asymmetries are sustainable with little or no objective differentiation and despite immediate competition between products. Two explanations for this observation were presented.

The first explanation focuses on the possibility that firms can create a local form of vertical differentiation through costly quality positioning of their products. If the cost of positioning is high enough, there is "room for only one high quality player in each market." The second explanation is that competing in multiple markets offers firms the possibility to engage in a collusive arrangement wherein large share markets with monopoly power are shared among competitors.

The contingency that spans both explanations is that sustenance of spatial concentration should be expected especially when goods are physically similar, i.e., when demand side arguments for asymmetric market shares are weak. If goods are the same, initial market conditions persist, whereas if products are differentiated, these initial market conditions will not be sustainable. Indeed, in the latter case, all competitors tend to compete for a "fair share" in all local markets. Thus, "initial market conditions," e.g., product launch strategies and early differences in perceived quality matter most in undifferentiated categories and are therefore strategically important in CPG industries. 


\section{References}

Anderson, Simon P., André de Palma (1988), "Spatial Price Discrimination with Heterogenous Products," the Review of Economic Studies, vol 55, 573-592.

— - (2001), "Product Diversity in Asymmetric Oligopoly: Is the Quality of Consumer Goods too Low?" the Journal of International Economics, vol 49, 113-135.

— - - and Jacques-François Thisse (1992), "Discrete Choice Theory of Product Differentiation," MIT press, Cambridge MA.

Bagwell, K. (2003), "The Economic Analysis of Advertising," forthcoming in the Handbook of Industrial Organization, Vol. 3, eds. Robert Porter and Mark Armstrong.

Berry, Steven, James Levinsohn and Ariel Pakes (1995), "Automobile Prices in Market Equilibrium," Econometrica, vol 63:4 (July), 841-890.

Bernheim, B. Douglas and Michael D. Whinston (1990), "Multi-market Contact and Collusive Behavior," Rand Journal of Economics, vol 21:1 (Spring), 1-26.

Bettman, James R. and C. Whan Park (1980), "Effects of Prior Knowledge and Experience and Phase of the Choice Process on Consumer Decision Processes: A Protocol Analysis," Journal of Consumer Research, 7 (December), 234-48.

Bowman, Douglas, and Hubert Gatignon (1996), "Order of Entry as a Moderator of the Effect of the Marketing Mix on Market Share," Marketing Science, vol 15:3, 222-242

Bronnenberg, Bart J., Sanjay Dhar, and Jean-Pierre Dubé (2005), "Market Structure and the Geographic Distribution of Brand Shares in Consumer Package Goods Industries," working paper.

Caplin, Andrew and Barry Nalebuff (1991), "Aggregation and Imperfect Competition: On the Existence of Equilibrium," Econometrica, vol 59, 26-61.

Carpenter, Gregory S, Rashi Glazer, and Kent Nakamoto (1994), "Meaningful Brands from Meaningless Differentiation: The Dependence on Irrelevant attributes," Journal of Marketing Research, vol 31:3 (Augustus), 339-350.

Comanor, W.S. and T.A. Wilson (1974), Advertising and Market Power, Cambridge, MA: Harvard University Press.

Dickson, Peter and Alan G. Sawyer (1990), "The Price Knowledge and Search of Supermarket Shoppers," Journal of Marketing, vol 54 (July), 42-53.

d'Aspremont C., J.J. Gabszewicz, and J.-F. Thisse (1979), "On Hotellings 'Stability in Competition,"' Econometrica, 47:1145-1150

Fujita, Masahisa, Paul Krugman, and Anthony J. Venables (1999), "The Spatial Economy: Cities, Regions and International Trade," MIT Press, Cambridge, MA. 
Golder, Peter N. and Gerard J. Tellis [1993], "Pioneer Advantage: Marketing Logic or Marketing Legend?" Journal of Marketing Research, 30 (May), 158-70

Greenhut, M.L (1981), "Spatial Pricing in the United States, West Germany, and Japan," Economica, vol 48, 79-86

Hoyer, Wayne D. (1984), "An Examination of Consumer Decision Making for a Common Repeat Purchase Product," Journal of Consumer Research, vol 11 (December), 822-829.

and Steven P. Brown (1990), "Effects of Brand Awareness on Choice for a Common, Repeat-Purchase Product," Journal of Consumer Research, 17 (September), 141-8.

Karnani, Aneel and Birger Wernerfelt (1985), "Multiple Point Competition," Strategic Management Journal, vol 6, 87-96

Kirmani, Amna, and Peter Wright (1989), "Money Talks: Perceived Advertising Expense and Expected Product Quality," Journal of Consumer Research, vol 16:3, 344-353

Klemperer, Paul (1992), "Equilibrium Product Lines: Competing Head to Head May Be Less Competitive," American Economic Review, 82:4, 740-755.

Moorthy, K. Sridhar (1988), "Product and Price Competition in a Duopoly," Marketing Science, vol 7:2 (Spring), 141-165.

Nevo, Aviv (2001), "Measuring Market Power in the Ready-to-Eat Cereal Category," Econometrica, 69(2), 307-342.

Nijs, Vincent R., Marnik G. Dekimpe, Jan-Benedict E.M. Steenkamp, and Dominique M. Hanssens (2002), "The Category Demand Effects of Price Promotions," Marketing Science, vol 20:1 (Winter), 1-22

Park, C. Whan and V. Parker Lessig (1981), "Familiarity and Its Impact on Consumer Biases and Heuristics," Journal of Consumer Research, 8 (September), 223-30.

Robinson, William T. and Claes Fornell (1985), "Sources of Market Pioneer Advantages in Consumer Goods Industries," Journal of Marketing Research, vol 22 (August), 305-317.

Simonson, Itamar (1993), "Get Closer to Your Customers by Understanding How They Make Choices," California Management Review, vol 35:4, Summer, 68-84.

Soberman, David (2002), "Questioning Conventional Wisdom about Competition in Differentiated Markets," Quantitative Marketing and Economics, 3:1, 41:70.

Trout, Jack and Steve Rivkin (2000), "Differentiate or Die," John Wiley \& Sons Inc., New York, NY.

Yarrow, George (1989), "The Kellogg's Cornflakes Equilibrium and Related Issues," Working paper, Hertford College, Oxford. 


\section{A Proofs}

Proof of proposition $1 \quad$ For convenience, drop all subscripts $m$. Recall that

$$
s_{1}=\frac{\exp \left[\left(a-p_{1}\right) / \mu\right]}{\exp \left[\left(a-p_{1}\right) / \mu\right]+\exp \left[\left(-p_{2}\right) / \mu\right]}, a=a_{1}-a_{2}
$$

Some useful relations are $\frac{d s_{1}}{d p_{1}}=-\frac{1}{\mu} s_{1}\left(1-s_{1}\right), \frac{d s_{1}}{d p_{2}}=\frac{1}{\mu} s_{1} s_{2}, \frac{d s_{1}}{d a}=\frac{1}{\mu} s_{1}\left(1-s_{1}\right)$. Taking the first order condition for firm 1 gives,

$$
F\left(p_{1}, p_{2}, a\right) \equiv p_{1}-c_{1}-\frac{\mu}{1-s_{1}}=0
$$

The total differential of this function is $F_{p_{1}} d p_{1}+F_{p_{2}} d p_{2}+F_{a} d a=0$. Writing $\Phi \equiv s_{1} / s_{2}$, it is easy to show that

$$
F_{p 1}=1-\frac{\mu \cdot d\left(1-s_{1}\right)^{-1}}{d p_{1}}=1-\mu\left(1-s_{1}\right)^{-2} \frac{d s_{1}}{d p_{1}}=1+\Phi
$$

It can further be shown that $F_{p 2}$ and $F_{a}$ are both equal to $-\Phi$. Substitution in the total differential for $F$ gives

$$
(1+\Phi) d p_{1}-\Phi d p_{2}-\Phi d a=0
$$

Now, totally differentiate the first order condition for firm 2 .

$$
G\left(p_{1}, p_{2}, a\right) \equiv p_{2}-c_{2}-\frac{\mu}{s_{1}}=0
$$

The total differential of this function is $G_{p_{1}} d p_{1}+G_{p_{2}} d p_{2}+G_{a} d a=0$. Once more it is easy to show that

$$
G_{p 1}=-\frac{1}{\Phi}, \quad G_{p 2}=1+\frac{1}{\Phi}, \quad G_{a}=\frac{1}{\Phi}
$$

Substitution in the total differential of $G$ gives

$$
-\frac{1}{\Phi} d p_{1}+\left(1+\frac{1}{\Phi}\right) d p_{2}+\frac{1}{\Phi} d a=0
$$

Finally, combining (A.4) and (A.7), gives that

$$
\frac{d p_{1}^{*}}{d a}=\frac{\Phi^{2}}{1+\Phi+\Phi^{2}}>0, \quad \frac{d p_{2}^{*}}{d a}=\frac{-1}{1+\Phi+\Phi^{2}}<0 .
$$

This proofs proposition 1. The result states further that changes in $a$ are never priced by the firm to the market completely. Indeed, it may be noted from the definition of $\Phi$ that the sensitivity of $p_{1}$ to changes in $a$ is always between 0 and 1 .

Proof of proposition 2 Once again, the subscript $m$ is dropped from the notation. It needs to be shown that the profits of both firms are convex in $a$. Thus, the second order derivative of profits with respect to $a$ needs to be evaluated at the equilibrium prices. It is sufficient that

$$
\frac{d\left(\frac{d \pi_{i}^{*}}{d q}\right)}{d a}=\frac{d^{2} \pi_{i}^{*}}{d a^{2}}=\frac{d^{2} p_{i}^{*}}{d a^{2}}>0, \quad i=1,2
$$


where the last equality relation follows from equation (6). To simplify the derivation, I can use the expressions in (A.8) and take the derivative of both expressions with respect to $a$.

$$
\frac{d^{2} p_{i}}{d a^{2}}=\frac{d f_{i}(\Phi)}{d \Phi} \frac{d \Phi}{d a}
$$

with $f_{i}(\Phi)$ given by the RHS of equation (A.8). It can be shown that

$$
\frac{d f_{1}(\Phi)}{d \Phi}=\frac{2 \Phi+\Phi^{2}}{\left(1+\Phi+\Phi^{2}\right)^{2}}>0 \quad \text { and } \quad \frac{d f_{2}(\Phi)}{d \Phi}=\frac{2 \Phi+1}{\left(1+\Phi+\Phi^{2}\right)^{2}}>0
$$

Recalling that $\Phi=\exp \left[\left(-p_{1}+p_{2}+a\right) / \mu\right]$, the derivative $d \Phi / d a$ of the ratio of shares at optimal prices with respect to $a$ is

$$
\begin{aligned}
\frac{d \Phi}{d a} & =\frac{d\left(\exp \left[\left(-p_{1}^{*}+p_{2}^{*}+a\right) / \mu\right]\right)}{d a} \\
& =\exp \left[\left(-p_{1}^{*}+p_{2}^{*}+a\right) / \mu\right] \times \frac{d\left(\left(-p_{1}^{*}+p_{2}^{*}+a\right) / \mu\right)}{d a} \\
& =\Phi \cdot \frac{1}{\mu}\left(-\frac{d p_{1}^{*}}{d a}+\frac{d p_{2}^{*}}{d a}+1\right) \\
& =\frac{1}{\mu} \frac{\Phi^{2}}{1+\Phi+\Phi^{2}}>0
\end{aligned}
$$

Substitution of (A.11) and (A.12) into (A.10) proves that the profits of both firms are convex in $a$.

Proof of proposition 3 Without loss in generality, I consider $a \geq 0$, or that firm 1 is positioned as good as or better than firm 2. This is without loss in generality because the opposite case just involves label switching of firm 1 and 2 . The derivative of profits $\pi_{i}$ with respect to $\mu$ and $a$ are equal to

$$
\frac{d^{2} \pi_{i}}{d(a) d(\mu)}=\frac{d^{2} p_{i}^{*}}{d(a) d(\mu)}
$$

Using equation (A.11), we can write,

$$
\frac{d^{2} \pi_{1}}{d(a) d(\mu)}=\frac{d f_{1}(\Phi)}{d \Phi} \frac{d \Phi}{d \mu}
$$

To sign $\frac{d \Phi}{d \mu}$, rearrange the definition of $\Phi$ at optimal prices to obtain the implicit equation that

$$
\Phi=\exp \left(\left(a-p_{1}^{*}+p_{2}^{*}\right) / \mu\right)
$$

with $p_{1}^{*}-c=\mu /\left(1-s_{1}\right)=\mu(1+\Phi), p_{2}^{*}-c=\mu /\left(1-s_{2}\right)=\mu\left(1+\Phi^{-1}\right)$. Thus, at optimal prices $\Phi=\exp \left(\frac{a}{\mu}-\Phi+\frac{1}{\Phi}\right)$, which is larger than 1 if $a>0$ (see proposition 1 ). From this equation, take the derivative to obtain that

$$
\frac{d \Phi}{d \mu}=-\exp \left(\frac{a}{\mu}-\Phi+\frac{1}{\Phi}\right)\left(\frac{a}{\mu^{2}}+\frac{d \Phi}{d \mu}+\frac{1}{\Phi^{2}} \frac{d \Phi}{d \mu}\right)=-\Phi\left(\frac{a}{\mu^{2}}+\frac{d \Phi}{d \mu}+\frac{1}{\Phi^{2}} \frac{d \Phi}{d \mu}\right)
$$


Rearranging gives that

$$
\frac{d \Phi}{d \mu}=-\frac{a}{\mu^{2}} \frac{\Phi^{2}}{\left(1+\Phi+\Phi^{2}\right)},
$$

which is strictly negative as long as $a>0$. Now, going back to equation (A.15), we get

$$
\begin{aligned}
\frac{d^{2} \pi_{1}}{d(a) d(\mu)} & =\frac{d f_{1}(\Phi)}{d \Phi} \frac{d \Phi}{d \mu} \\
& =-\frac{a}{\mu^{2}}(2+\Phi)\left(\frac{\Phi}{\left(1+\Phi+\Phi^{2}\right)}\right)^{3}<0
\end{aligned}
$$

A similar proof holds for firm 2. Thus, the smaller $\mu$, the more positive (for firm 1) and the less negative (for firm 2) an impact of an increase in $a$ on profits for both firms.

Proof of proposition 4 This result is implied by proposition 1. If both firms have high perceived quality they both set prices of $c+2 \mu$. These prices stem from $p_{i}^{*}=c_{i}+\mu /\left(1-s_{i}\right)$, and from the obvious result that if both have the same positioning $s_{i}=1 / 2$. It is easily verified that there are no unilateral deviations from this proposed equilibrium.

\section{Proof of proposition 5}

1. Proof is the same as that given in the text preceding proposition 1

(a) It needs to be shown that $\mu(\Phi-1)-\mu\left(1-\Phi^{-1}\right)$ is decreasing in $\mu$. For any quality gap $a$

$$
\mu(\Phi-1)=\int_{0}^{a}\left(\frac{d \pi_{1}}{d \alpha}\right) d \alpha \text { and } \mu\left(1-\Phi^{-1}\right)=-\int_{0}^{a}\left(\frac{d \pi_{2}}{d \alpha}\right) d \alpha
$$

Or,

$$
\mu(\Phi-1)-\mu\left(1-\Phi^{-1}\right)=\int_{0}^{a}\left(\frac{d \pi_{1}}{d \alpha}+\frac{d \pi_{2}}{d \alpha}\right) d \alpha
$$

Taking derivatives with respect to $\mu$, and using proposition 3 gives the final result, i.e., because both $\frac{d^{2} \pi_{1}}{d \alpha d \mu}$ and $\frac{d^{2} \pi_{2}}{d \alpha d \mu}$ are negative

$$
\int_{0}^{a}\left(\frac{d^{2} \pi_{1}}{d \alpha d \mu}+\frac{d^{2} \pi_{2}}{d \alpha d \mu}\right) d \alpha<0
$$

(b) It is obvious that $\lim _{\mu \downarrow 0} \mu\left(1-\Phi^{-1}\right)=0$. Applying l'Hopital's rule to $\lim _{\mu \downarrow 0} \mu(\Phi-1)$, I get

$$
\lim _{\mu \downarrow 0} \mu(\Phi-1)=\lim _{\mu \downarrow 0}-\frac{\Phi^{\prime}}{1 / \mu^{2}}=\lim _{\mu \downarrow 0} \frac{\left(a_{h}-a_{\ell}\right) \Phi^{2}}{\left(1+\Phi+\Phi^{2}\right)}=\left(a_{h}-a_{\ell}\right)
$$

For $\mu \rightarrow \infty$, again, applying l'Hopital's rule,

$$
\lim _{\mu \rightarrow \infty} \mu(\Phi-1)=\lim _{\mu \rightarrow \infty}-\frac{\Phi^{\prime}}{1 / \mu^{-2}}=\lim _{\mu \rightarrow \infty} \frac{\left(a_{h}-a_{\ell}\right) \Phi^{2}}{\left(1+\Phi+\Phi^{2}\right)}=\frac{\left(a_{h}-a_{\ell}\right)}{3} .
$$


Further,

$$
\lim _{\mu \rightarrow \infty} \mu\left(1-\Phi^{-1}\right)=\lim _{\mu \rightarrow \infty}-\frac{\Phi^{\prime}}{\Phi^{2} / \mu^{-2}}=\lim _{\mu \rightarrow \infty} \frac{\left(a_{h}-a_{\ell}\right)}{\left(1+\Phi+\Phi^{2}\right)}=\frac{\left(a_{h}-a_{\ell}\right)}{3} .
$$

This completes the proof.

Proof of proposition 6 Suppose that firms set quality sequentially, with firm 1 choosing first. Depending on the combination of firm 1's and firm 2's quality choices, firm 2 receives at optimal prices payoffs $\pi_{2}\left(a_{1}, a_{2}\right)$ as follows:

$$
\begin{array}{rcc}
\pi_{2}\left(a_{h}, a_{h}\right)=\mu-K\left(a_{h}\right) & \text { if } & a_{1}=a_{h}, a_{2}=a_{h} \\
\pi_{2}\left(a_{\ell}, a_{h}\right)=\Phi \mu-K\left(a_{h}\right) & \text { if } & a_{1}=a_{\ell}, a_{2}=a_{h} \\
\pi_{2}\left(a_{h}, a_{\ell}\right)=\Phi^{-1} \mu-K\left(a_{\ell}\right) & \text { if } & a_{1}=a_{h}, a_{2}=a_{\ell} \\
\pi_{2}\left(a_{\ell}, a_{\ell}\right)=\mu-K\left(a_{\ell}\right) & \text { if } & a_{1}=a_{\ell}, a_{2}=a_{\ell}
\end{array}
$$

First, use these payoffs to derive the response functions of firm 2 . If firm 1 plays $a_{h}$ then

$$
\pi_{2}=\left\{\begin{array}{ll}
\pi_{2}\left(a_{h}, a_{h}\right), \quad \text { and } a_{2}=a_{h} \text { if } \quad \mu\left(1-\Phi^{-1}\right)>\Delta K \\
\pi_{2}\left(a_{h}, a_{\ell}\right), \quad \text { and } a_{2}=a_{\ell} \text { if } \quad \mu\left(1-\Phi^{-1}\right)<\Delta K
\end{array},\right.
$$

whereas, if firm 1 plays $a_{\ell}$ then,

$$
\pi_{2}=\left\{\begin{array}{lll}
\pi_{2}\left(a_{\ell}, a_{h}\right), & \text { and } a_{2}=a_{h} \text { if } \quad \mu(\Phi-1)>\Delta K \\
\pi_{2}\left(a_{\ell}, a_{\ell}\right), & \text { and } a_{2}=a_{\ell} \text { if } \quad \mu(\Phi-1)<\Delta K
\end{array}\right.
$$

Note that $\left(1-\Phi^{-1}\right)<(\Phi-1)$. Given that firm 1 moves first, it can use all this knowledge. To do so it has to consider three scenarios.

1. Case I: $\Delta K<\mu\left(1-\Phi^{-1}\right)$ where firm 2 always plays $a_{h}$. In this case, firm 1 also plays $a_{h}$.

2. Case II: $\mu\left(1-\Phi^{-1}\right)<\Delta K<\mu(\Phi-1)$, where firm 2 always plays the opposite of firm 1 . If firm 1 plays $a_{h}$, then firm 2 plays $a_{\ell}$, and firm 1's profit is $\mu \Phi-K\left(a_{h}\right)$. If firm 1 plays $a_{\ell}$ then firm 2 plays $a_{h}$ and firm 1's profts are $\mu \Phi^{-1}-K\left(a_{\ell}\right)$. Hence firm 1 will play $a_{h}$ if profits are higher than when playing $a_{\ell}$, i.e., $\mu \Phi-K\left(a_{h}\right)>\mu \Phi^{-1}-K\left(a_{\ell}\right)$, or:

$$
\Delta K<\mu\left(\Phi-\Phi^{-1}\right)
$$

Is this always true in case II? Case II implies that $\mu\left(1-\Phi^{-1}\right)<\Delta K<\mu(\Phi-1)$. Because $\mu(\Phi-1)<\mu\left(\Phi-\Phi^{-1}\right), \Delta K<\mu(\Phi-1)$ implies that $\Delta K<\mu\left(\Phi-\Phi^{-1}\right)$. Hence, with asymmetric equilibria (case II), firm 1 will always position at $a_{h}$.

3. Case III: $\Delta K>\mu(\Phi-1)$, where firm 2 always plays $a_{\ell}$. In this case, it is easy to see that firm 1 plays $a_{\ell}$.

\section{Proof of proposition 7}


1. Let firm 1 be positioned at $a_{h}$ in market 1 while firm 2 is positioned at $a_{\ell}$. In market 2 the opposite happens. Denote the ratio of output of product 1 to that of product 2 at optimal prices in market 1 again by $\Phi \equiv s_{11}^{*} / s_{21}^{*}$. Further, denote the equilibrium profits of firm $i$ by $\pi_{i}^{*} \equiv \sum_{m} \pi_{i m}^{*}=\pi_{i 1}^{*}+\pi_{i 2}^{*}$. Given equal cost, the prices of products mirror each other across markets, i.e. $p_{11}^{*}=p_{22}^{*}$, and $p_{12}^{*}=p_{21}^{*}$. From the definition of the ratio of outputs, it is therefore obvious that in market $2, s_{12}^{*} / s_{22}^{*}=\Phi^{-1}$. By proposition $1, \Phi>1$, i.e., in market 1 , firm 1 is the product with the higher perceived quality, prices, and demand. Equations (5) and (6) give that

$$
\pi_{i m}^{*}=\frac{s_{i m}}{1-s_{i m}} \cdot \mu-K
$$

Therefore, with asymmetric positioning, multi-market profits are

$$
\pi_{i}^{*}=\sum_{m} \pi_{i m}^{*}=\left(\Phi+\Phi^{-1}\right) \mu-2 K, i=1,2 .
$$

From this formulation it is clear that profit is lowest when $\Phi=1$. Therefore the following inequality always holds

$$
\mu \Phi+\mu \Phi^{-1}-2 K \geq 2 \mu-2 K
$$

2. The second part of the proposition implies that existing reciprocal asymmetries are sustainable - even when breaking them is free- as long as firms value future profits sufficiently. Specifically, firm 1 resists the temptation to reposition from $a_{\ell}$ to $a_{h}$ if a periodic profit of $\pi_{i}^{*}$, is valued higher than a one time profit of $\pi_{i}^{d}$ followed by a periodic profit of $\pi_{i}^{0}$. This valuation is met for all discount rates $\delta$ that satisfy

$$
\pi_{i}^{*}\left(1+\delta+\delta^{2}+\cdots\right)>\pi_{i}^{d}+\pi_{i}^{0}\left(\delta+\delta^{2}+\delta^{3} \cdots\right) .
$$

Hence, when $\delta>\delta^{*} \equiv \frac{\pi_{i}^{d}-\pi_{i}^{*}}{\pi_{i}^{d}-\pi_{i}^{0}}=\frac{1}{\Phi}$ firm 1 does not reposition. By symmetry, the same holds for firm 2 .

3. I need to show that $\frac{d \delta^{*}}{d \mu}>0$ or equivalently that $\frac{d \Phi}{d \mu}<0$ as long as $\Phi>1$. This was already shown in equation (A.18) 